\title{
The Mediterranean Diet: Socio-cultural Relevance for Contemporary Health Promotion
}

\author{
Surinder Phull ${ }^{*}$ \\ University of West London, Wendy Wills, University of Hertfordshire, Angela Dickinson, University of Hertfordshire, \\ United Kingdom
}

\begin{abstract}
In biomedical literature, The Mediterranean Diet describes a healthy eating model, based on epidemiological findings on the predominant eating practices in Crete and Southern Italy in the 1960s. At the time, the level of life expectancy in this region was amongst the highest worldwide and rates of cardiovascular disease were amongst the lowest. Medical research has since given increasing attention to this dietary pattern and its potential health benefits. The various components of The Mediterranean Diet are fast becoming a paradigm for healthier lifestyles as well as potential model for weight loss. In 2010 UNESCO recognised The Mediterranean Diet as an intangible cultural heritage of Italy, Spain, Greece and Morocco and the diet has moved away from a uniquely biomedical model to a cultural representation. This has led to increased recognition of the importance of social and cultural context in the dietary model, particularly the idea of conviviality, the pleasure of shared meals. It has also brought to light the debate over the cultural legitimacy of The Mediterranean Diet and its ability to represent the cultural diversity of the region. This literature review consolidates interdisciplinary perspectives on the cultural context of the Mediterranean Diet. A literature search was conducted using both biomedical and social science databases to reflect the interdisciplinary nature of the article. This review explores the relevance of the dietary model as global public health tool as well as examining the role of pleasurable eating in health promotion.
\end{abstract}

Keywords: Food culture, Mediterranean diet, public health nutrition.

\section{THE MEDITERRANEAN DIET: A CULTURAL REP- RESENTATION}

The Mediterranean Diet is recognised internationally as an evidence-based biomedical model for healthy eating, a paradigm for healthier lifestyles and an effective tool for weight loss [1-5]. Medical interest in the diet of the Mediterranean originates from the Seven Countries Study; a largescale epidemiological project conducted by Harvard physiologist Ancel Keys in the 1950s [6], which made associations with the diet of Southern Europe [in particular Southern Italy and Crete] and low levels of cardiovascular disease. Seven Countries was the stimulus for a significant body of nutritional research that established The Mediterranean Diet as a biomedical concept. Since then nutritional research, for the most part, has taken a reductionist approach to the analysis of various foods consumed in the region in order to validate adherence to the whole diet model $[2,7,8]$. Definitions of the diet have been developed over the last 60 years and The Mediterranean Diet pyramid, a graphic representation of the nutritional model, was created by the Harvard School of Public Health in 1993. Country-specific versions of the pyramid have since been re-designed to represent varying food habits in the region $[9,10]$ and experts in the field have developed KIDMED, a scoring system that can measure adherence to the diet by assessing weekly consumption of

*Address correspondence to this author at the University of West London, United Kingdom; Tel: 02082094071; E-mail: Surinder.Phull@uwl.ac.uk foods integral to this eating pattern [11]. Evidence on the health potential of the diet is based on adherence to these scientifically recognised dietary criteria.

In the scientific arena, The Mediterranean Diet is largely regarded as a biomedical concept that positions foods eaten in the region within a nutritional mainframe. Social scientists have long questioned the use of the cultural significance of term 'Mediterranean' in a model, which appears to be a predominantly American construct. However, in recent years there has been a move within the Mediterranean region to embrace the socio-cultural context of the diet. In Spain, Greece and Italy, experts in nutrition and public health have adapted health promotional materials to give greater emphasis to Mediterranean traditions, food culture and lifestyles, focusing on the importance of convivial mealtimes. In 2013, UNESCO recognised The Mediterranean Diet as intangible cultural heritage of Italy, Spain, Greece and Morocco [12, 13]. The biomedical model has been re-framed in its original cultural context.

In fact, the idea of The Mediterranean Diet as a cultural model is not necessarily a new one. The author of the Seven Countries Study, Ancel Keys, was certainly aware of the socio-cultural context of the diet and made no secret of his affection for Southern Europe [14]. His fondness for the region was made clear in a descriptive account on a visit to Italy in the 1960s:

Snowflakes were beginning to fly as we left Strasbourg on the $4^{\text {th }}$ of February. All the way to Switzerland we drove in a snowstorm.... On the Italian side the air was mild, flow- 
ers were gay, birds were singing and we basked at the outdoor table drinking our first espresso coffee at the Domodosola. We felt warm all over... [15].

Keys' attachment to the region demonstrates the difficulty in isolating foods eaten in the Mediterranean from their social and cultural context. Yet, from a public health perspective, embracing The Mediterranean Diet as a cultural model poses two distinct problems. Firstly, in terms of foods, there may be a disparity between the 'Mediterranean Diet' as defined by nutritionists and public opinion about the diet of the region. What do those living in the region understand as Mediterranean foods? Do those outside of the region perceive this differently? Secondly, to what extent is The Mediterranean Diet seen as a cultural template that involves adopting the eating behaviours of the region? The nutritional model is now embedded within cultural ideas about convivial, leisurely eating. Are these habits genuinely reflective of lifestyles within the region and are those outside the region being asked to adopt a lifestyle and socio-cultural shift that is feasible?

This review will look at challenges to promoting The Mediterranean Diet within and outside the Mediterranean region. It will evaluate how accurately the cultural ideals recognised by UNESCO represent the region and how culturally acceptable these ideals are to populations outside of the Mediterranean. The article is based on a literature review using both biomedical and social science databases to reflect the interdisciplinary nature of the review. The following databases were used: MEDLINE, CINHAL, EMBASE, Psych Info, Scopus, Academic Search Elite. Social Policy Info and Google Scholar using the terms Mediterranean Diet, culture, society and history.

\section{MEDITERRANEAN DIET WITHIN THE REGION: A CULTURAL REPRESENTATION}

The focus on the socio-cultural context of The Mediterranean Diet has been driven by public health experts within the region and has paralleled its UNESCO recognition [13]. The 2013 UNESCO report highlights that the context of food consumption is a fundamental aspect of the Mediterranean Diet. The act of eating together is seen to promote cultural identity and ensures social continuity. The Mediterranean Diet is esteemed as an opportunity for social exchange, communication and the promotion of community values and hospitality. Women are perceived to be at the hub of this cultural process through the safeguarding of culinary techniques and the transmission of the social values at the core of the diet [16].

The move away from the biomedical concept of The Mediterranean Diet towards a regionally driven cultural definition has been of interest to social scientists within the region but not without contention. For social anthropologists, the term Mediterranean Diet is still perceived as a mythical American construct that continues to mirror US dietary guidelines. It has been suggested that the dietary model, rather than representing cultural practices, has been reinvented to conform to nutritional ideals [17]. For example, in Spain food heritage products such as cured hams, products and regional cheeses are barely represented despite their cultural significance for the populations of the country [18].
This concept of 'inventing' a regional diet is not an idea that is unique to the Mediterranean. Murcott [19] explores the way in which food acts as a tool to solidify national identity. She argues that nationhood is a malleable concept that is continuously imagined and re-created and a nation's associated cuisines may be re-invented in the same way. Mintz [20] applies this theory to the invention of French haute cuisine that was established as a means of distinguishing the dominant social classes. Impressions of The Mediterranean Diet in cookbooks, health websites and the popular press, promote a very particular Mediterranean way of eating that reinforces ideas about regional identity. These are not necessarily a reality but the product of numerous self-perpetuating discourses. However unlike haute cuisine that was established from within France [21, 22], The Mediterranean Diet is an American invention that offered an idealistic cultural context to a nutritional regime from an outsider's perspective.

Concern has also been expressed about the use of the term 'Mediterranean' to describe the varying dietary practices of a large region [23]. The geographical, economic and cultural diversity of the Mediterranean basin poses a challenge to the idea of one Mediterranean Diet - the culinary features of a Moroccan diet are very different to those of Crete or Italy for example. The idea of encompassing culturally distinct food practices into one definition is seen as fundamentally questionable [24]. The homogenous concept of The Mediterranean Diet is perceived to devalue the rich culinary diversity and cooking skills present in the region. Culinary practices not only differ between countries but also within regions. A study of the Cerdanya Valley in the Pyrenees demonstrated clear distinction in the choice, preparation and consumption of foods in the French owned territory compared to the Spanish region [25]. With such a marked difference in a geographical area of just a few kilometres, how is it possible to represent the multiplicity of practices in the Mediterranean basin within one model? So how can the generic Mediterranean Diet have cultural significance to the populations within the region?

Nutritional experts have also questioned the geographical parameters of the diet, which appear to be unjustifiably Eurocentric [23, 26, 27]. The diet of Northern Italy, for example, does not sit easily within the nutritional boundaries of the model; Malta has a unique dietary pattern and only a very small region of France is influenced by Mediterranean food culture [27, 28]. Conversely, with the exception of Morocco, the African and Asian countries within the Mediterranean basin are rarely referred to in the context of the diet, despite their populations eating diets that match the principles of the model [Medina 2004].

Even within the better-represented countries there have been questions over whether The Mediterranean Diet represents cultural norms and food practices. It has been argued that the 'healthy and frugal' Mediterranean Diet discovered by Keys, was driven by economic limitations in the $1950 \mathrm{~s}$ and 1960s, a way of eating based on necessity rather than desire [29, 30]. Recently, economic growth and globalisation of food production have been cited as the reason for the desertion of The Mediterranean Diet in the countries from which it originated [31-33]. Many of the major food items in 
The Mediterranean Diet pyramid have increased in price, whereas cheaper refined foods are more affordable [34]. If The Mediterranean Diet was once 'poor man's food', today the reverse appears to be true [35]. Lower socioeconomic status is inversely associated with The Mediterranean Diet in the region, and high nutrition knowledge and higher education levels are positively associated with this dietary pattern, suggesting that The Mediterranean Diet is a concept that is taught rather than being a cultural norm [36-38]. Recent statistics go as far as to suggest that The Mediterranean Diet is in a 'moribund state' in its alleged birthplace of Crete [39]. Obesity and diet related disease are rising rapidly in the Mediterranean [40, 41] and therefore there is a concerted drive to promote the diet regionally. It appears that the UScreated 'Mediterranean Diet' is being imported into its cultural birthplace.

The regional desertion of The Mediterranean Diet brings a major question to the forefront. In the light of globalisation, can The Mediterranean Diet be legitimised as a cultural representation? This question is as important from a cultural heritage perspective as it is from the view of health promotion. If populations are to maintain a dietary pattern, they need to be clear what that patterns is. If there is mismatch between what the public and health professionals deem to be traditional Mediterranean foods and Mediterranean food culture, adherence to the nutritionally desirable diet may be problematic.

\section{MEDITERRANEAN DIET AS A GLOBAL HEALTH TOOL}

In many respects, outside of the Mediterranean, the concept of the diet is much clearer. As a global public health tool, The Mediterranean Diet does not claim to be an allencompassing cultural representation but rather a cultural reference point for healthy eating practices $[42,43]$. The strategic cherry picking of the best elements of Mediterranean traditions has certainly created a useful "whole diet model' that has had beneficial impact on populations in Northern Europe [44, 45]. Numerous studies illustrate that the adoption of food choices typical of Mediterranean countries may be beneficial in metabolic and vascular diseases [46]. Ironically, although overall adherence to this 'model' of eating has decreased within the Mediterranean, in Northern Europe there has been growing acceptance of the diet pyramid [11,31, 47].

Yet are populations following a cultural model or simply a set of dietary recommendations not dissimilar to those in any nutritional model? An article published in Public Health Nutrition suggested that the term 'Mediterranean Diet' is a misnomer and that this generic healthy eating pattern can be applied to a number of regional cuisines [48]. The biomedical scoring system for the diet is certainly based on generic foods [49] and therefore the benefits of the diet may be related to more general healthy eating patterns. Populations, arguably, do not need Mediterranean foods to enjoy the health promoting benefits of the diet. In fact, in order to maintain cultural heritage and promote sustainability it may be more useful to promote regionally specific diets. The Nordic Diet promoted in Scandinavian countries is an example of this and has been proposed as an alternative to the
Mediterranean model $[50,51]$. Promotional materials supporting The Mediterranean Diet recognise sustainability local production and preservation of culture as an integral part of the model [52, 53]. Proponents of the Nordic Diet argue that this focus on regional cuisines and local, sustainable foods should apply to countries all over Europe [54, 55].

A further issue is the cultural relevance of the diet. For many populations the idea of adopting a Mediterranean Diet might seem culturally restrictive. Certainly, Italian, Greek and Spanish dishes are widely consumed all over Europe, yet so are Indian, Chinese, and Japanese foods. The idea of a world cuisine has become a reality [56]. In this climate it is hard to know whether The Mediterranean Diet [or any other regional diet] is a suitable starting point or a culturally, restrictive model that does not reflect the culinary diversity many populations have become accustomed to.

To add another layer of complexity of this issue, countries such as the UK are ethnically diverse and it is often minority ethnic groups that are primary targets for nutrition education due to increased genetic susceptibility to obesity and diet related disease [57]. Due to its proven track record in preventing diet related disease, promoting an adapted Mediterranean Diet has been discussed as a tool for prevention of cardiovascular disease in South Asian populations [58]. This may be seem like a logical step for South Asians in the UK but whether it is a culturally appropriate one is questionable. Current NICE guidelines in health promotion stipulate that health initiatives for ethnic groups should accommodate varying degrees of cultural identification [59]. It may be more appropriate for the diverse populations to modify their current eating patterns rather than adopt a culturally specific but potentially alien 'diet'.

From a nutritional perspective, The Mediterranean Diet model is an effective tool in clinical or experimental settings, yet when promoting the diet to global populations, public health experts need to consider whether it is sustainable and culturally appropriate. Dietary practices are embedded in the structures and routines of ordinary living and have to be compatible with this. Experiences of food and ways of eating go beyond biomedical notions of healthy eating and may be related to social and cultural acceptability [60].

\section{THE ROLE OF CONVIVIAL EATING IN HEALTH PROMOTION}

The most prominent cultural ideal that is promoted in The Mediterranean Diet model is the idea of conviviality, the pleasure of shared meals. It is perhaps this notion of pleasure that really sets The Mediterranean Diet apart from other dietary tools, and arguably other dietary cultures. The diet is often described as 'palatable' [61] and there is a focus on local food and recipes. From a public health perspective the Mediterranean Diet, recognises that for dietary advice to be sustainable it must be pleasurable. This sits in contrast to dietary advice in the UK, where the majority of dietary advice is based on rules, reduction of food groups or foods consumed and essentially deprivation - with very little attention given to palatability, culinary tradition, sharing meals or indeed pleasure $[62,63]$. 
Sociological literature suggests that this difference is representative of a disparity in cultural norms. Research on food choice indicates that Southern European populations give greater importance to sociability and cooking and enjoying food with others whereas UK and US populations give more attention to convenience, choice and health [64-67]. Evidence also suggests that focusing on health and convenience is a barrier to traditional food consumption [68]. Quantitative data indicates that populations in Spain and France spend longer eating than those in the UK [69]. This is viewed as an indicator of the sociality of mealtimes, given that the duration of a meal has been shown to increase according to the number of people eating [70]. Cross-cultural studies have suggested that populations that prioritize pleasure over health demonstrate healthier eating behaviours [70, 71]. Fischler [17] suggests that the divide between Northern and Southern European eating patterns is not so much a question of individual attitudes but in the cultural norms around eating. This divide, it has been argued, is not geographical but in fact religious and draws a clear divide between Catholic and Protestant nations, the former favouring ideological worship and the latter focusing on personal responsibility for oneself [61].

If values regarding pleasure and sociality are deeply embedded in the fabric of Mediterranean society, it would seem wholly appropriate to include 'pleasurable eating' as part of the dietary model for the region. Yet when we use the model outside of the region, is this focus on pleasure appropriate or perhaps is it more prudent to focus on the scientific ideals of nutrition?

Making this cultural distinction may be problematic to populations both within the Mediterranean and in Northern Europe and Scandinavia. Firstly, in Northern Europe and the US, although nutritional concepts are culturally accepted, this does not mean they are effective in achieving better eating habits [72]. Health professionals are struggling to deal with the rise of obesity and diet related disease in recent years. It is clear that in the current obesogenic environment, the austere voice of nutrition is lost amidst competing interests from food industries and the media [73]. On the other hand, in this environment, it may be argued that focusing on pleasure is detrimental to public health. The Mediterranean Diet of the 1950s and 1960s was consumed in a setting where populations were physically active and diet was based on local plant foods. In the current environment where populations are faced with an overabundance of calorific food, achieving the balance between pleasurable eating and health may be more troublesome.

Yet, there is evidence that focusing on pleasure may result in better dietary habits [70,71]. There is also suggestion that the dominant socio-cultural discourses on food may be changing in Westernised countries and there is a cultural shift from pragmatism to pleasure. The idea of pleasure in food is a very recent discourse with the promotion of cookbooks, speciality food and wine magazines and TV cooking shows [74]. Yet in order to appreciate whether ideas of pleasure and conviviality can and should be promoted in a global nutrition arena, it is important to recognise that 'pleasurable eating' may not be accessible to all sectors of society. De Vault suggests that shared meals have different meanings to families according to their socio-economic status. For richer families commensal meals may be an opportunity for pleasure and self-expression but for poorer ones mealtimes may be meeting simple necessities [75]. In this light, does socio-economic status put constraints on conviviality?

The role of social class on food consumption has given rise to numerous sociological theories, exploration of which is beyond the remit of this paper. One theory worth noting however is the idea of distinction developed by French sociologist Pierre Bourdieu [76]. Food, 'taste' and eating practices can be seen as a means of social distinction and offer form of cultural capital to higher social classes, with value attached to culturally authorised tastes. The Mediterranean Diet is a paradoxical reflection of this theory. The prototype diet was based on affordable, local produce, a diet adopted by the rural working classes in times of economic challenge and food scarcity [77]. The US re-invention of the diet, has led to worldwide recognition as a fashionable way of eating in a health-conscious world. The diet offers 'cultural capital' and has been imported back into the region by the higher social classes $[38,78]$. This does not only apply to the foods within the diet but the lifestyle and way of eating that it promotes. If in contemporary societies pleasurable eating is linked to economic freedom, this ideal may not be relevant to all sectors of society.

Given the clear links between low socio-economic status, poor health and obesity $[57,79]$, it is a priority that health messages are accessible to all sectors of society. Further research is needed to gain clarity as to what pleasurable eating means to different populations and whether the practice of eating convivially, is accessible and relevant to general populations.

\section{CONCLUSION}

There has been a concerted drive to create a broader concept of The Mediterranean Diet and this awareness that has led to the creation of a model that incorporates tradition, social eating and pleasurable dining within the nutritional mainframe. Recognising pleasure as a fundamental part of a sustainable eating pattern is a unique component of the Mediterranean Diet. It takes a step away from most dietary models that focus on the role of diet to meet biological needs rather than the role of foods as a vehicle for cultural processes and social interactions. Yet the inclusion of these principles is only a first step. Further research is needed to examine whether principles of convivial eating are representative of current eating practices in the Mediterranean and whether these principles are compatible with sustainable, healthy eating on a global level. Research needs go beyond examining the validity of the nutritional components of The Mediterranean Diet and explore the legitimacy of its cultural ideals.

\section{CONFLICT OF INTEREST}

The author confirms that this article content has no conflict of interest.

\section{ACKNOWLEDGEMENTS}

Declared none. 


\section{REFERENCES}

[1] Buckland G, Bach A, Serra-Majem L. Obesity and the Mediterranean diet: a systematic review of observational and intervention studies. Obesity Rev 2008; 9(6): 582-93.

[2] Sofi F, Cesari F, Abbate R, Gensini GF, Casini A. Adherence to Mediterranean diet and health status: meta-analysis. BMJ 2008; 337: a1344.

[3] Beunza JJ, Toledo E, Hu FB, et al. Adherence to the Mediterranean diet, long-term weight change, and incident overweight or obesity: the Seguimiento Universidad de Navarra (SUN) cohort. Am J Clin Nutr 2010; 92(6): 1484-93.

[4] Arvaniti F, Priftis KN, Papadimitriou A, et al. Adherence to the Mediterranean type of diet is associated with lower prevalence of asthma symptoms, among 10-12 years old children: the PANACEA study. Ped Allergy Immunol 2011; 22(3): 283-9.

[5] Sofi F, Abbate R, Gensini GF, Casini A. Accruing evidence on benefits of adherence to The Mediterranean Diet on health: an updated systematic review and meta-analysis. Am J Clin Nutr 2010; 92(5): 1189-96.

[6] Keys A, Menotti A, Karvonen MJ, et al. The diet and 15-year death rate in the seven countries study. Am J Epidemiol 1986; 124(6): 903-15.

[7] Steffen LM, Jacobs DR,Jr, Stevens J, Shahar E, Carithers T, Folsom AR. Associations of whole-grain, refined-grain, and fruit and vegetable consumption with risks of all-cause mortality and incident coronary artery disease and ischemic stroke: the Atherosclerosis Risk in Communities (ARIC) Study. Am J Clin Nutr 2003; 78(3): 383-90.

[8] Psaltopoulou T, Naska A, Orfanos P, Trichopoulos D, Mountokalakis T, Trichopoulou A. Olive oil, the Mediterranean diet, and arterial blood pressure: the Greek European Prospective Investigation into Cancer and Nutrition (EPIC) study. Am J Clin Nutr 2004; 80(4): 1012-8

[9] Noah A, Truswell AS. There are many Mediterranean diets. Asia Pac J Clin Nutr 2001; 10(1): 2-9.

[10] Dernini S, Berry EM, Bach-Faig A, et al. A dietary model constructed by scientists. Paris: CIHEAM-SciencesPo Les Presses, 2012; pp. 71-88.

[11] Serra-Majem L, Ribas L, Ngo J, et al. Food, youth and The Mediterranean Diet in Spain. Development of KIDMED, Mediterranean Diet Quality Index in children and adolescents. Public Health Nutr 2004; 7(07): 931-5.

[12] Xavier Medina F. Mediterranean diet, culture and heritage: challenges for a new conception. Public Health Nutr 2009; 12(9A): $1618-20$

[13] Bach-Faig A, Berry EM, Lairon D, et al. Mediterranean diet pyramid today. Science and cultural updates. Public Health Nutr 2011; 14(12A): $2274-84$

[14] Keys A. Mediterranean diet and public health: personal reflections. Am J Clin Nutr 1995; 61(6 Suppl): 1321S-3.

[15] Keys A, Keys M. How to eat well and stay well the Mediterranean Way. New York: Doubleday \& Company 1975.

[16] UNESCO. <br />Representative List of the Intangible Cultural Heritage of Humanity. 2013; Available at: http://www.unesco.org/ culture/ich/RL/00884. [Accessed 4/29, 2014].

[17] Fischler C. El modelo alimentario mediterraneo: mito y/o realidad. In: Medina F, Ed. La alimentacion mediterranea. $1^{\text {st }}$ ed. Barcelona: Institut Catala de la Mediterranea 1996.

[18] Xavier MF. Mediterranean diet, culture and heritage: challenges for a new conception. Public Health Nutr 2009; 12(9A): 1618-20.

[19] Murcott A, Henry V. Food as an expression of identity. The future of the nation state: Essays on cultural pluralism and political integration 1996; pp. 21-37.

[20] Mintz SW, Du Bois CM. The anthropology of food and eating. Annu Rev Anthropol 2002; 31: 99-119.

[21] Ferguson PP. A cultural field in the making: Gastronomy in 19thcentury France 1. Am J Sociol 1998; 104(3): 597-641.

[22] Trubek AB. Haute cuisine: How the French invented the culinary profession. University of Pennsylvania Press 2000

[23] Medina F. Dieta y alimentacion en el area mediterranea. Reflexiones sobre algunos conceptos controverdios. In: Guigoni A, ed. Foodscapes: stili mode culture del cibo ogg: Polimetrica sas 2004. pp. 151-66.
[24] Contaldo F, Pasanisi F, Mancini M. Beyond the traditional interpretation of Mediterranean diet. Nutr Metabol Cardiovas Dis 2003; 13(3): 117-9.

[25] Macbeth HM. Food preferences and taste: continuity and change. Berghahn Books 1997.

[26] Simopoulos AP. The Mediterranean diets: What is so special about the diet of Greece. The scientific evidence. J Nutr 2001; 131(11 Suppl): 3065S-73.

[27] de Lorgeril M, Salen P, Paillard F, Laporte F, Boucher F, de Leiris J. Mediterranean diet and the French paradox: two distinct biogeographic concepts for one consolidated scientific theory on the role of nutrition in coronary heart disease. Cardiovasc Res 2002 ; 54(3): 503-15.

[28] Ferro-Luzzi A, Sette S. The Mediterranean Diet: an attempt to define its present and past composition. Eur J Clin Nutr 1989; 43 Suppl 2:13-29.

[29] Gonzalez TI. Introducción: Modelos ideales y realidad en alimentación. In: Junta de Andalucia/Fundacion Machado, Eds. Antropologia de la alimentación. Nuevos ensayos sobre la dieta mediterrhnea 1996.

[30] de Garine I. Alimentacion mediterraneene et realite. In: Gonzalez Turmo I, Romero de Solis P, Ed. Antropología de la alimentación: nuevos ensayos sobre la dieta mediterránea 1996.

[31] Bach-Faig A, Fuentes-Bol C, Ramos D, et al. The Mediterranean Diet in Spain: adherence trends during the past two decades using the Mediterranean Adequacy Index. Public Health Nutr 2011; 14(4): 622-8.

[32] El Rhazi K, Nejjari C, Romaguera D, et al. Adherence to a Mediterranean diet in Morocco and its correlates: cross-sectional analy sis of a sample of the adult Moroccan population. BMC Public Health 2012; 12: 345.

[33] Leon-Munoz LM, Guallar-Castillon P, Graciani A, et al. Adherence to The Mediterranean Diet pattern has declined in Spanish adults. J Nutr 2012; 142(10): 1843-50.

[34] Bonaccio M, Iacoviello L, de Gaetano G, Moli-Sani I. The Mediterranean diet: the reasons for a success. Thromb Res 2012; 129(3): 401-4.

[35] Ciezadilo A. Does the mediterranean diet even exist? New York Times 2011.

[36] Bonaccio M, Iacoviello L, de Gaetano G, Moli-Sani Investigators. The Mediterranean diet: the reasons for a success. Thromb Res 2012; 129(3): 401-4.

[37] Gonzalez Jimenez E, Aguilar Cordero MJ, Garcia Garcia CJ, et al. Influence of family environment of the development of obesity and overweight in a population of school children in Granada (Spain). Nutr Hosp 2012; 27(1): 177-84.

[38] Bonaccio M, Di Castelnuovo A, Costanzo S, et al. Nutrition knowledge is associated with higher adherence to Mediterranean diet and lower prevalence of obesity. Results from the Moli-sani study. Appetite 2013; 68: 139-46.

[39] Alexandratos N. The Mediterranean Diet in a world context. Public Health Nutr 2006; 9(1A): 111-7.

[40] Martín AR, Nieto JMM, Ruiz JPN, Jiménez LE. Overweight and obesity: the role of education, employment and income in Spanish adults. Appetite 2008; 51(2): 266-72.

[41] Farajian P, Risvas G, Karasouli K, et al. Very high childhood obesity prevalence and low adherence rates to The Mediterranean Diet in Greek children: the GRECO study. Atherosclerosis 2011; 217(2): 525-30.

[42] Ferro-Luzzi A, Sette S. The Mediterranean Diet: an attempt to define its present and past composition. Eur J Clin Nutr 1989; 43(Suppl 2): 13-29.

[43] Ferro-Luzzi A, Branca F. Mediterranean diet, Italian-style: prototype of a healthy diet. Am J Clin Nutr 1995; 61(Suppl 6): 1338S45.

[44] Papadaki A, Scott JA. The Mediterranean eating in Scotland experience project: evaluation of an Internet-based intervention promoting the Mediterranean diet. Br J Nutr 2005; 94(2): 290-8.

[45] Willett WC. The Mediterranean diet: science and practice. Public Health Nutr 2006; 9(1A): 105-10.

[46] Zazpe I, Estruch R, Toledo E, et al. Predictors of adherence to a Mediterranean-type diet in the PREDIMED trial. Eur J Nutr 2010; 49(2): 91-9.

[47] Casini L, Contini C, Marone E, Romano C. Food Habits. Changes among Italians in the last ten years. Appetite 2013; 68: 21-9. 
[48] Bere E, Brug J. Is the term 'Mediterranean diet' a misnomer? Public Health Nutr 2010; 13(12): 2127-9.

[49] Mariscal-Arcas M, Rivas A, Velasco J, Ortega M, Caballero AM, Olea-Serrano F. Evaluation of The Mediterranean Diet Quality Index (KIDMED) in children and adolescents in Southern Spain. Public Health Nutr 2009; 12(09): 1408-12.

[50] Olsen A, Egeberg R, Halkjaer J, Christensen J, Overvad K, Tjonneland A. Healthy aspects of the Nordic diet are related to lower total mortality. J Nutr 2011; 141(4): 639-44.

[51] Mithril C, Dragsted LO, Meyer C, Blauert E, Holt MK, Astrup A. Guidelines for the new Nordic diet. Public Health Nutr 2012; 15(10): 1941-7.

[52] Burlingame B, Dernini S. Sustainable diets: The Mediterranean Diet as an example. Public Health Nutr 2011; 14(12A): 2285-7.

[53] Medina FX. Food consumption and civil society: Mediterranean diet as a sustainable resource for the Mediterranean area. Public Health Nutr 2011; 14(12A): 2346-9.

[54] Bere E, Brug J. Towards health-promoting and environmentally friendly regional diets: a Nordic example. Public Health Nutr 2009; 12(01): 91-6.

[55] Saxe H, Larsen TM, Mogensen L. The global warming potential of two healthy Nordic diets compared with the average Danish diet. Clim Change 2013; 116(2): 249-62.

[56] Goody J. Industrial food: towards the development of a world cuisine. Food Cult 1997; pp. 338-53.

[57] Rennie K, Jebb S. Prevalence of obesity in Great Britain. Obesity Rev 2005; 6(1): 11-2.

[58] Singh RB, Dubnov G, Niaz MA, et al. Effect of an IndoMediterranean diet on progression of coronary artery disease in high risk patients (Indo-Mediterranean Diet Heart Study): a randomised single-blind trial. The Lancet 2002; 360(9344): 1455-61.

[59] Netto G, Bhopal R, Lederle N, Khatoon J, Jackson A. How can health promotion interventions be adapted for minority ethnic communities? Five principles for guiding the development of behavioural interventions. Health Promot Int 2010; 25(2): 248-57.

[60] Nielsen A, Korzen S, Holm L. Inverting the Food Pyramid? Social and cultural acceptability of Walter Willet's dietary recommendations among young people with weight concerns. Appetite 2008; 51: $178-86$.

[61] Willett WC, Sacks F, Trichopoulou A, et al. Mediterranean diet pyramid: a cultural model for healthy eating. Am J Clin Nutr 1995; 61(6 Suppl): 1402S-6.

[62] Food Standards Agency. The Eat Well Plate. www.nhs.uk/Livewell/Goodfood/Pages/eatwell-plate.aspx 2014.

[63] NHS. Healthy Eating. 2014; Available at: www.nhs.uk/livewell/healthy-eating. [Accessed 06/15, 2014].
[64] Pettinger C, Holdsworth M, Gerber M. Psycho-social influences on food choice in Southern France and Central England. Appetite 2004; 42(3): 307-16.

[65] Pettinger C, Holdsworth M, Gerber M. Meal patterns and cooking practices in Southern France and Central England. Public Health Nutr 2006; 9(8): 1020-6.

[66] Rozin P, Fischler C, Shields C, Masson E. Attitudes towards large numbers of choices in the food domain: a cross-cultural study of five countries in Europe and the USA. Appetite 2006; 46(3): 304-8.

[67] Gately A, Caraher M, Lang T. A qualitative, cross cultural examination of attitudes and behaviour in relation to cooking habits in France and Britain. Appetite 2014; 75: 71-81.

[68] Pieniak Z, Verbeke W, Vanhonacker F, Guerrero L, Hersleth M. Association between traditional food consumption and motives for food choice in six European countries. Appetite 2009; 53(1): 101-8.

[69] OECD. Special Focus: Measuring Leisure in OECD countries. Society at a Glance 2009: OECD social indicators: OECD 2009; pp. 19-49.

[70] Rozin P, Remick AK, Fischler C. Broad themes of difference between French and Americans in attitudes to food and other life domains: personal versus communal values, quantity versus quality, and comforts versus joys. Front Psychol 2011; 2: 177.

[71] Rozin P, Bauer R, Catanese D. Food and life, pleasure and worry, among American college students: gender differences and regional similarities. J Personality Soc Psychol 2003; 85(1): 132-41.

[72] Holm L. Cultural and social acceptability of a healthy diet. Eur J Clin Nutr 1993; 47(8): 592-9.

[73] Lang T, Rayner G. Overcoming policy cacophony on obesity: an ecological public health framework for policymakers. Obesity Rev 2007; 8(s1): 165-81.

[74] Banwell C, Broom D, Davies A, Dixon J. Weight of modernity. $1^{\text {st }}$ ed. London: Springer 2012.

[75] DeVault ML. Feeding the family: the social organization of caring as gendered work. University of Chicago Press 1994.

[76] Bourdieu P. Distinction: A social critique of the judgement of taste. Harvard University Press 1984.

[77] Las muchas memorias del hambre. La alimentación mediterránea: historia, cultura, nutrición: Icaria 1996.

[78] Bonaccio M, Bonanni AE, Di Castelnuovo A, et al. Low income is associated with poor adherence to a Mediterranean diet and a higher prevalence of obesity: cross-sectional results from the Molisani study. BMJ Open 2012; 2(6): 10.1136/bmjopen-2012-001685. Print 2012.

[79] Zaninotto P, Head J, Stamatakis E, Wardle H, Mindell J. Trends in obesity among adults in England from 1993 to 2004 by age and social class and projections of prevalence to 2012. J Epidemiol Comm Health 2009; 63(2): 140-6.

This is an open access article licensed under the terms of the Creative Commons Attribution Non-Commercial License (http://creativecommons.org/licenses/by-nc/3.0/) which permits unrestricted, non-commercial use, distribution and reproduction in any medium, provided the work is properly cited. 